\title{
Adsorption of COD in Coking Wastewater on Nitric Acid-Modified Blue Coke Activated Carbon
}

\author{
Xu Jiang $\mathbb{D}^{1,2}$ Xinzhe Lan, ${ }^{1}$ Yonghui Song, ${ }^{1}$ and Xiangdong Xing $\mathbb{i D}^{1}$ \\ ${ }^{1}$ School of Metallurgical Engineering, Shaanxi Province Metallurgical Engineering and Technology Research Centre, \\ Xi'an University of Architecture and Technology, Xi'an 710055, China \\ ${ }^{2}$ Research Institute of Energy and Chemical Industry, Xianyang Vocational Technical College, Xianyang 712000, China \\ Correspondence should be addressed to Xiangdong Xing; xaxingxiangdong@163.com
}

Received 25 September 2019; Accepted 18 November 2019; Published 6 December 2019

Guest Editor: Hassan M. A. Hassan

Copyright (c) $2019 \mathrm{Xu}$ Jiang et al. This is an open access article distributed under the Creative Commons Attribution License, which permits unrestricted use, distribution, and reproduction in any medium, provided the original work is properly cited.

\begin{abstract}
The blue coke activated carbon (BAC) modified by nitric acid at different concentrations was used as an adsorbent to remove COD from coking wastewater. Characterization of BAC was performed using $\mathrm{N}_{2}$ adsorption/desorption techniques, scanning electron microscope (SEM), Fourier transform infrared spectroscopy (FTIR), and Boehm titration. The results showed the BrunnerEmmet-Teller (BET) specific surface area and iodine value of BAC became higher after modification, and the adsorption capacity of BAC for coking wastewater was effectively improved with nitric acid modification. The optimal nitric acid concentration for modification was $3 \mathrm{~mol} / \mathrm{L}$ (BAC-N3), which had more acid functional group contents than unmodified. The chemical oxygen demand (COD) removal rate was to reach $77.05 \%$ when $4 \mathrm{~g}$ BAC-N3 was added into $50 \mathrm{~mL}$ coking wastewater in 120 min with a shaking speed of $100 \mathrm{rpm}$ at $25^{\circ} \mathrm{C}$. Langmuir model could better describe equilibrium adsorption data by BAC-N3, and the kinetic study showed that the adsorption process was best fitted by the pseudo-second-order kinetic model.
\end{abstract}

\section{Introduction}

Blue coke consists of solid carbon materials and is prepared by medium- and low-temperature dry distillation with Jurassic nonstick coal and slightly caked coal as raw materials, which are widespread in the Shaan-Gan-Ning-Meng-Jin Region of northwestern China [1]. In these areas, blue coke plays an important role in the coal chemical industry because of its high fixed carbon content, specific resistance, chemical activity, and low ash content, sulfur content, phosphorus content, and volatility [2].

Nowadays, carbon solid wastes are used as raw materials for the preparation of activated carbon (AC) in addition to traditional wood, fruit shell, and coal [3-5]. Blue coke powder, a by-product of blue coke production, transportation, and storage, has a grain size of less than $6 \mathrm{~mm}$ and has been associated with environmental challenges [6]. However, blue coke powder offers potential as a high-quality and cheap raw material for $\mathrm{AC}$ production because of its previously mentioned characteristics. A type of BAC was prepared from blue coke powder using $\mathrm{KOH}$ activation by Song et al. [2], yielding a product with a $733.48 \mathrm{mg} / \mathrm{g}$ iodine adsorption value at $800^{\circ} \mathrm{C}$. BAC with a BET specific surface area of $738.75 \mathrm{~m}^{2} / \mathrm{g}$ was prepared by steam activation at $900^{\circ} \mathrm{C}[6]$. Mesoporous BAC, with a BET specific surface area reaching $513.62 \mathrm{~m}^{2} / \mathrm{g}$, was prepared by Tian et al. through $\mathrm{KOH}$ activation within microwave [7]. However, the above BAC suffers from drawbacks of pore structure irregularity, low surface area, disordered pore size distribution, and limited surface chemical properties. For obtaining quality AC according to different purposes, physical and chemical modifications were employed to adjust the pore structure and improved the surface chemical properties of $\mathrm{AC}$, which have important significance for the development of $\mathrm{AC}$ industry.

Acid oxidation modification is one of the common methods that can dredge the AC-blocked pores, improve pore structure, and increase the number of oxygen-containing functional groups on the surface and enhance their hydrophilicity. Many scholars have studied AC modification 
by using nitric acid, which is a commonly used modifier [8]. Soltani et al. [9] modified cigarette filter AC by using nitric acid under different concentrations and contact time, and the AC had more mesopores and had a $57.8 \%$ increase in the surface acidity compared to the nonmodified AC. Tong et al. [10] found that modification by nitric acid can increase the number of oxygen-containing functional groups and nitrogen-containing functional groups in the AC surface and improve the adsorption effect on mercury. Zhang et al. [11] studied the adsorption of benzothiophene in simulated gasoline by nitric acid-modified AC and found a $33.7 \%$ increase in absorption capacity after modification. Babel et al. [12] investigated the $\mathrm{HNO}_{3}$ - and $\mathrm{H}_{2} \mathrm{SO}_{4}$-modified AC's ability to remove $\mathrm{Cr}(\mathrm{VI})$ from synthetic wastewater, and they found that the $\mathrm{HNO}_{3}$-modified $\mathrm{AC}$ exhibits an improved adsorption effect because the number of oxygencontaining functional groups was increased by the modification, which caused electrostatic attraction, hydrophobic interaction, and chemical bonding.

Coking wastewater, which is produced from coking, gas purification, and chemical product recovery, is a highly concentrated, highly polluting, and highly toxic industrial organic wastewater. Coking wastewater is harm to the environment due to its high concentration of $\mathrm{NH}_{4}{ }^{+}-\mathrm{N}$, phenols, poison, and its difficult degradation by using organisms [13]. Moreover, AC is widely used to treat coking wastewater because of its simple operation, strong adsorption, good stability, and convenient regeneration. Many scholars have done a lot of research studies on physical structure and chemical property improvements of AC and enhancement of adsorption effect, and these studies have been made a lot of achievements. To date, however, few studies have directly addressed modification of BAC which was prepared by blue coke powder.

Although nitric acid is one of the most common AC modifiers, few studies have focused on the BAC which was prepared by disused blue coke powder. In this paper, BAC was modified using nitric acid at different concentrations. We analyzed the effect of the modification on pore structure and surface chemical properties. Then, the optimal technological process and adsorption thermodynamics and kinetics of COD from coking wastewater onto BAC were studied for the modified AC technology and reasonable discharge of coking wastewater.

\section{Materials and Methods}

2.1. Materials. The blue coke powder was provided by a blue coke enterprise in Shaanxi Province, China. The industrial and elemental analyses of which are shown in Table 1. As shown in Table 1, the blue coke powder has more ash content, which is significantly higher than other raw materials of AC.

The experimental coking wastewater was obtained from a coal chemical enterprise in Shaanxi Province, and the main index of which is presented in Table 2.

The reagents used in the experiment were as follows: $\mathrm{HNO}_{3}, \mathrm{AgSO}_{4}, \mathrm{Na}_{2} \mathrm{~S}_{2} \mathrm{O}_{3}, \mathrm{~K}_{2} \mathrm{Cr}_{2} \mathrm{O}_{7}, \mathrm{HCl}, \mathrm{H}_{2} \mathrm{SO}_{4},\left(\mathrm{NH}_{4}\right)$ $2 \mathrm{Fe}\left(\mathrm{SO}_{4}\right)_{2} \cdot 6 \mathrm{H}_{2} \mathrm{O}, \mathrm{I}_{2}, \mathrm{KI}$, starch indicator, and ferrous metal indicator, all of which were analytically pure.
TABle 1: Proximate and elemental analyses of blue coke powder.

\begin{tabular}{lccccccccc}
\hline & \multicolumn{4}{c}{ Proximate analysis } & \multicolumn{4}{c}{ Elemental analysis } \\
\hline $\begin{array}{l}\text { Blue } \\
\text { coke }\end{array}$ & $M_{\mathrm{t}}$ & $A_{\mathrm{ad}}$ & $V_{\mathrm{ad}}$ & $\mathrm{FC}_{\mathrm{ad}}$ & $C_{\mathrm{ad}}$ & $O_{\mathrm{ad}}$ & $H_{\mathrm{ad}}$ & $N_{\mathrm{ad}}$ & $S_{\mathrm{t} \text { ad }}$ \\
powder & 2.15 & 16.77 & 12.07 & 69.01 & 72.88 & 0.3 & 1.06 & 0.88 & 0.6 \\
\hline
\end{tabular}

Note: $M_{t}$ is the total moisture content, $A_{a d}$ is the ash content as air dry basis, $V_{a d}$ is the volatile content as air dry basis, $\mathrm{FC}_{a d}$ is the fixed carbon content as air dry basis, $C_{a d}$ is the carbon element content as air dry basis, $O_{a d}$ is the oxygen element content as air dry basis, $H_{a d}$ is the hydrogen element content as air dry basis, $N_{a d}$ is the nitrogen element content as air dry basis, and $S_{\mathrm{t}, \text { ad }}$ is the sulphur element content as air dry basis.

TABLe 2: Main index of coking wastewater.

\begin{tabular}{ccccc}
\hline & $\begin{array}{c}\mathrm{COD} \\
(\mathrm{mg} / \mathrm{L})\end{array}$ & $\begin{array}{c}\mathrm{NH}_{4}{ }^{+}-\mathrm{N} \\
(\mathrm{mg} / \mathrm{g})\end{array}$ & Phenol $(\mathrm{mg} / \mathrm{g})$ & $\mathrm{pH}$ \\
\hline Coking wastewater & 3604 & 303.15 & 911.26 & 8.74 \\
\hline
\end{tabular}

\subsection{Methods}

2.2.1. Preparation of BAC. BAC was produced via steam activation at $900^{\circ} \mathrm{C}$, which is based on a preliminary study [7], and yielded a product termed BAC-0.

2.2.2. Modification of BAC. BAC was modified by nitric acid as follows: under the room temperature, $10 \mathrm{~g}$ of $\mathrm{BAC}-0$ was impregnated with $50 \mathrm{~mL}$ of $\mathrm{HNO}_{3}$ (the concentrations were $1 \mathrm{~mol} / \mathrm{L}, 2 \mathrm{~mol} / \mathrm{L}, 3 \mathrm{~mol} / \mathrm{L}$, and $4 \mathrm{~mol} / \mathrm{L}$, respectively) in a joined conical bottle that was placed in a rotating water bath oscillator (HY-8) for $4 \mathrm{~h}$ at a shaking speed of $100 \mathrm{rpm}$. Afterward, the mixture was filtered and the solid was washed with sufficient distilled water until the $\mathrm{pH}$ of the solution closed to neutral. The resulting materials were termed as BAC-N1, BAC-N2, BAC-N3, and BAC-N4, respectively.

\subsubsection{Adsorption of Coking Wastewater}

Effect of Modification Conditions. $5 \mathrm{~g}$ of BACs was dispersed in a conical bottle containing $50 \mathrm{~mL}$ of coking wastewater, respectively. The mixture was then agitated at $25^{\circ} \mathrm{C}$ in a rotating water bath oscillator at $100 \mathrm{rpm}$ for $4 \mathrm{~h}$ for equilibrium. The COD removal rate could be calculated using the following equation:

$$
\begin{aligned}
\text { COD removal rate } & =\frac{c_{o}-c_{e}}{c_{o}} \times 100 \%, \\
q_{e} & =\frac{\left(c_{0}-c_{e}\right) V}{m},
\end{aligned}
$$

where $q_{e}$ is the equilibrium adsorption capacity $(\mathrm{mg} / \mathrm{g}), c_{o}$ is the COD of the raw coking wastewater $(\mathrm{mg} / \mathrm{L}), c_{e}$ is the COD of coking wastewater after adsorption equilibrium $(\mathrm{mg} / \mathrm{L}), m$ is the addition amount of adsorbent $(\mathrm{g})$, and $V$ is the volume of coking wastewater (L).

Effect of Addition Amount and Isothermal Adsorption Experiment. A predetermined amount of adsorbent was 
dispersed in a conical bottle containing $50 \mathrm{~mL}$ of coking wastewater. The mixture was agitated at $25^{\circ} \mathrm{C}$ in a rotating water bath oscillator at $100 \mathrm{rpm}$ for $4 \mathrm{~h}$. The COD removal rate and equilibrium adsorption capacity were calculated using equations (1) and (2), respectively. The Langmuir and Freundlich equations were used to fit the isothermal adsorption process.

Influence of Shaking Speed and Adsorption Kinetics Experiment. The optimum addition amount of optimal adsorbents was dispersed in a conical bottle containing $50 \mathrm{~mL}$ of coking wastewater. The mixture was agitated in a rotating water bath oscillator at $25^{\circ} \mathrm{C}$. The shaking speed was set at $0 \mathrm{rpm}$, $100 \mathrm{rpm}$, and $200 \mathrm{rpm}$, and sampling was performed at $10 \mathrm{~min}, 30 \mathrm{~min}, 60 \mathrm{~min}, 90 \mathrm{~min}, 120 \mathrm{~min}, 150 \mathrm{~min}$, and $180 \mathrm{~min}$. The $q_{t}$ and COD removal rate were calculated using equations (3) and (1), respectively:

$$
q_{t}=\frac{\left(c_{0}-c_{t}\right) V}{m}
$$

where $q_{t}$ is the adsorption capacity of time $t(\mathrm{mg} / \mathrm{g})$ and $c_{t}$ is the COD of coking wastewater at time $t(\mathrm{mg} / \mathrm{L})$.

\subsection{Characterization of Prepared BAC and Coking} Wastewater. The COD was determined by GB 11914-1989 (China). Iodine number was determined by GB/T 7702.72008 (China). The yield ( $Y$ ) was estimated from the mass ratio of modified BAC to unmodified BAC. The BET specific surface area and pore structure of the BAC were obtained using a fully automatic physical adsorption apparatus (ASAP2420) by a nitrogen adsorption/desorption isotherm that was determined at $77.35 \mathrm{~K}$. The morphology of the BACs was examined by scanning electron microscopy (JSM$6700 \mathrm{~F})$. The functional groups on the surface of the BAC were identified by Fourier transform infrared spectroscopy.

In general, although the kind and relative content of surface functional group of BAC can be analysed by FTIR, the actual content cannot be obtained. Well, the Boehm titration can solve this problem perfectly. According to the definition of the Boehm titration, the alkaline solutions with different basicity can only react with different acidity functional group on the surface of BAC. For example, $\mathrm{NaHCO}_{3}$ only reacts with carboxyl group, $\mathrm{Na}_{2} \mathrm{CO}_{3}$ can react with carboxyl and lactone groups, and $\mathrm{NaOH}$ can react with carboxyl group, lactone group, and phenolic hydroxyl group. Similarly, $\mathrm{HCl}$ can neutralize the basic functional group on the surface of BAC.

The determination method is as follows: $1.00 \mathrm{~g}$ of BAC was impregnated with in four $100 \mathrm{~mL}$ conical bottles, respectively, which impregnated in $50 \mathrm{~mL}$ of $\mathrm{HCl}, \mathrm{NaOH}$, $\mathrm{Na}_{2} \mathrm{CO}_{3}$, and $\mathrm{NaHCO}_{3}$ solution, respectively (the concentration is $0.05 \mathrm{~mol} / \mathrm{L}$ ). These were placed in a rotating water bath oscillator for $48 \mathrm{~h}$ at $25^{\circ} \mathrm{C}$ with a shaking speed of $100 \mathrm{rpm}$. Afterward, the solution was filtered and stored in sealed condition. $10 \mathrm{~mL}$ of $\mathrm{HCl}$ filtrate was added into a conical bottle which was titrated with $0.05 \mathrm{~mol} / \mathrm{L} \mathrm{NaOH}$ solution. $10 \mathrm{~mL}$ of $\mathrm{NaOH}, \mathrm{Na}_{2} \mathrm{CO}_{3}$, and $\mathrm{NaHCO}_{3}$ filtrate was added into the conical bottle, respectively, which were titrated with $0.05 \mathrm{~mol} / \mathrm{L} \mathrm{HCl}$ solution. The consumption of $\mathrm{HCl}$ and $\mathrm{NaOH}$ solution can be calculated.

The specific calculation method of functional groups content is as follows:

(i) The content of basic functional group ( $\left.n_{\text {basicity }}\right)$ The $\mathrm{HCl}$ neutralized the basic functional group on the surface of BAC, and the consumption of $\mathrm{HCl}\left(n_{\mathrm{HCl}}\right.$, consume) can be calculated by $\mathrm{NaOH}$ titration, which equals the content of basic functional group:

$$
n_{\text {basicity }}=n_{\mathrm{HCl}, \text { consume }} \text {. }
$$

(ii) The content of carboxyl group $\left(n_{\mathrm{ROOH}}\right)$

The $\mathrm{NaHCO}_{3}$ neutralized the carboxyl group on the surface of BAC, and the consumption of $\mathrm{NaHCO}_{3}$ ( $\left.n_{\mathrm{NaHCO}, \text { consume }}\right)$ can be calculated by $\mathrm{HCl}$ titration, which equals the content of carboxyl group:

$$
n_{\mathrm{ROOH}}=n_{\mathrm{NaHCO}_{3}, \text { consume}}
$$

(iii) The content of lactone group ( $n_{\mathrm{RCOOCOR}}$ )

The $\mathrm{Na}_{2} \mathrm{CO}_{3}$ neutralized with carboxyl and lactone groups on the surface of BAC, the consumption of $\mathrm{Na}_{2} \mathrm{CO}_{3}\left(n_{\mathrm{Na} 2 \mathrm{CO} \text {, consume }}\right)$ can be calculated by $\mathrm{HCl}$ titration, and the content of lactone group is calculated as follows:

$n_{\mathrm{RCOOCOR}}=n_{\mathrm{Na}_{2} \mathrm{CO}_{3}, \text { consume }}-n_{\mathrm{NaHCO}_{3}, \text { consume }}$.

(iv) The content of phenolic hydroxyl group $\left(n_{\mathrm{AROH}}\right)$

The $\mathrm{NaOH}$ neutralized with carboxyl group, lactone group, and phenolic hydroxyl group on the surface of BAC, the consumption of $\mathrm{NaOH}\left(n_{\mathrm{NaOH} \text {,consume }}\right)$ can be calculated by $\mathrm{HCl}$ titration, and the content of phenolic hydroxyl group is calculated as follows:

$$
n_{\mathrm{AROH}}=n_{\mathrm{NaOH}, \text { consume }}-n_{\mathrm{Na}_{2} \mathrm{CO}_{3} \text {, consume }}
$$

(v) The content of acidity functional group ( $n_{\text {acidity }}$ )

The content of acidity functional group equals the consumption of $\mathrm{NaOH}$ solution $\left(n_{\mathrm{NaOH} \text {,consume }}\right)$, and it is also equal to the sum of $n_{\text {acidity, }} n_{\mathrm{AROH}}$, $n_{\mathrm{RCOOCOR}}$, and $n_{\mathrm{ROOH}}$.

$$
n_{\text {Acidity }}=n_{\mathrm{NaOH}, \text { consume }}=n_{\mathrm{AROH}}+n_{\mathrm{RCOOCOR}}{ }^{\prime}+n_{\mathrm{ROOH}} .
$$

\section{Results and Discussion}

\subsection{Adsorbent Characterization}

3.1.1. Effect of Pore Structure. The pore structure parameters, iodine value yield, and ash content of BACs are shown in Table 3. The iodine value and BET specific surface area of BAC after modification were higher than those of unmodified, and the value increased with concentration rising from $1 \mathrm{~mol} / \mathrm{L}$ to $3 \mathrm{~mol} / \mathrm{L}$. This finding was partly because the blue coke powder, which was the raw material of BAC, 
TABLE 3: Pore structure parameters, iodine value yield, and ash content of BACs.

\begin{tabular}{|c|c|c|c|c|c|c|c|c|c|}
\hline Sample & $\begin{array}{c}S_{\mathrm{BET}} \\
\left(\mathrm{m}^{2} \cdot \mathrm{g}^{-1}\right)\end{array}$ & $\begin{array}{c}S_{\text {micro }} \\
\left(\mathrm{m}^{2} \cdot \mathrm{g}^{-1}\right)\end{array}$ & $\begin{array}{c}V_{\text {total }} \\
\left(\mathrm{cm}^{3} \cdot \mathrm{g}^{-1}\right)\end{array}$ & $\begin{array}{c}V_{\text {micro }} \\
\left(\mathrm{cm}^{3} \cdot \mathrm{g}^{-1}\right)\end{array}$ & $\begin{array}{c}V_{\text {micro }} / V_{\text {total }} \\
(\%)\end{array}$ & $\begin{array}{c}d_{\text {ave }} \\
(\mathrm{nm})\end{array}$ & $\begin{array}{l}\text { Iodine value } \\
\left(\mathrm{mg} \cdot \mathrm{g}^{-1}\right)\end{array}$ & $Y(\%)$ & $A_{a d}$ \\
\hline BAC-0 & 641.84 & 469.17 & 0.3720 & 0.2011 & 54.06 & 2.318 & 738.75 & - & 16.64 \\
\hline $\begin{array}{l}\text { BAC- } \\
\text { N1 }\end{array}$ & 693.59 & 435.14 & 0.3427 & 0.2020 & 58.94 & 2.008 & 776.14 & 87.23 & 2.16 \\
\hline $\begin{array}{l}\text { BAC- } \\
\text { N2 }\end{array}$ & 739.14 & 483.69 & 0.3744 & 0.2209 & 59.00 & 2.026 & 789.99 & 85.36 & 1.93 \\
\hline $\begin{array}{l}\text { BAC- } \\
\text { N3 }\end{array}$ & 801.51 & 519.38 & 0.3977 & 0.2374 & 59.69 & 1.985 & 828.17 & 82.41 & 1.61 \\
\hline $\begin{array}{l}\text { BAC- } \\
\text { N4 }\end{array}$ & 689.13 & 448.47 & 0.3460 & 0.2077 & 60.03 & 1.976 & 751.70 & 78.19 & 1.57 \\
\hline
\end{tabular}

Note: $S_{\mathrm{BET}}$ is the BET specific surface area, $S_{\text {micro }}$ is the microporous specific surface area, $V_{\text {total }}$ is the total pore volume, $V_{\text {micro }}$ is the microporous pore volume, $V_{\text {micro }} / V_{\text {total }}$ is the micropore ratio, and $d_{\text {ave }}$ is the average pore size.

exhibited significantly more ashes than other raw materials of AC. Thus, a large number of ashes remained on the BAC will block the pores, nitric acid can dissolve them. This function is called hole-throughing. This process was further aggravated with the increase in concentration. As seen from Table 3, the ash content of BACs after nitric acid modification reduces obviously. Meanwhile, the carbon activity sites in the surface of BAC exhibited high affinity, and these activity sites reacted with nitric acid molecules, which is a strong oxidizer. Thus, a small amount of carbon on the surface has been dissolved and the pore surface was etched, more micropore structures were formed, and this process is called hole-making function. The higher the nitric acid concentration, the more the microporosity, and the microporous specific surface area and microporous pore volume of BAC were then increased. This finding indicated that the yield of BAC decreases slightly with the increase in concentration, which proved that as nitric acid reacts with BAC, the pore structure was improved.

However, the BET specific surface area was reduced from $801.51 \mathrm{~m}^{2} \cdot \mathrm{g}^{-1}$ to $689.13 \mathrm{~m}^{2} \cdot \mathrm{g}^{-1}$ and the total pore volume was reduced from $0.3977 \mathrm{~cm}^{3} \cdot \mathrm{g}^{-1}$ to $0.3460 \mathrm{~cm}^{3} \cdot \mathrm{g}^{-1}$, when the concentration reached $4 \mathrm{~mol} / \mathrm{L}$, and the microporous specific surface area, microporous pore volume, and iodine value decreased as well. This is probably because nitric acid oxidation enhanced at this time, the BAC corrosion was serious, and the skeleton of some micropores was damaged, which resulted in significant pore wall thinning, and the additional mesopores and macropores were formed from the collapse of micropores, and the hole-enlargement function took place and became dominant. Furthermore, the collapsed carbon in the BAC and the oxygen-containing functional groups produced by nitric acid oxidation would plug the pores [14], and these were caused by the decline of the pore structure parameters and the iodine adsorption value also. Similar conclusions were obtained by Gi1 [15], who exhibited a significantly increasing trend in the porosity and the BET specific surface area after acid oxidation.

3.1.2. Surface Morphology of BACs. SEM was used to observe the surface physical morphology of the BACs. The SEM images of the BAC that was modified at different concentrations are shown in Figure 1.
As shown in Figure 1(a), there are many circular pores with different apertures in the material surface, which were formed into a honeycomb cavernous structure [16]. Figure 1 also shows that the BAC modified by nitric acid has more honeycomb-like shape and rough surface than unmodified, and the pore of BAC is nearly ellipse. The surface morphology of the material was different with varied nitric acid concentration. The etching of nitric acid mainly develops from the surface to the interior, and the higher the nitric acid concentration is, the more the activity effect occurs on material etching. Thus, the pore quantity of BAC increased, and the layered structure and honeycomb pore on the local area of the material surface became evident as the concentration increased. When the nitric acid concentration increased to $4 \mathrm{~mol} / \mathrm{L}$, the nitric acid oxidation was intense and the etching actions aggravated. Figure 1(e) illustrates that the number of micropores in BAC-N4 is markedly reduced, large pores rose, and the pore structure on the surface of BAC is irregular after modification. However, the overmodification led to a large number of pores of big- and medium-size collapse inside the BAC-N4 while some pores were blocked, reducing the BET specific surface area of BACN4. This result was consistent with that presented in Table 3.

3.1.3. Effect of Surface Chemical Properties. In general, besides the pore structure, the surface chemical properties of BAC will be changed after nitric acid modification. The FTIR spectra of BAC-0 and BAC-N3 are shown in Figure 2.

Figure 2 illustrates that BAC-0 and BAC-N3 have similar changes in the FTIR spectra. The absorption bands at $3250-3650 \mathrm{~cm}^{-1}$ were due to the $\mathrm{O}-\mathrm{H}$ stretching vibration of hydroxyl and carboxyl groups or due to the adsorbed water molecules during BAC steam activation preparation. The peak strength of BAC-N3 was larger than that of BAC-0, showing that the BAC-N3 exhibited additional oxygencontaining groups, such as hydroxyl and carboxyl. Correlated bands were centered at $1570-1700 \mathrm{~cm}^{-1}$, which could be attributed to the stretching of $\mathrm{C}=\mathrm{O}$ and/or $\mathrm{C}=\mathrm{C}$ on carboxyl, lipophilic, and unsaturated hydrocarbons in the BAC surface. The peak strength increased after modification, proving that additional carboxyl groups and their derivatized groups were present in the inner part and surface of the BAC-N3. The bands at $1000-1250 \mathrm{~cm}^{-1}$ were attributed to 


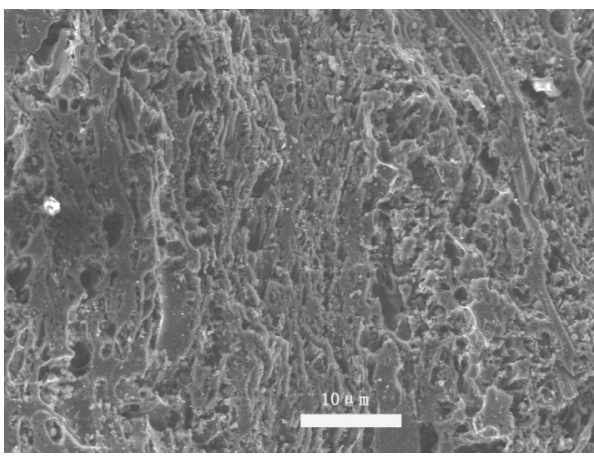

(a)

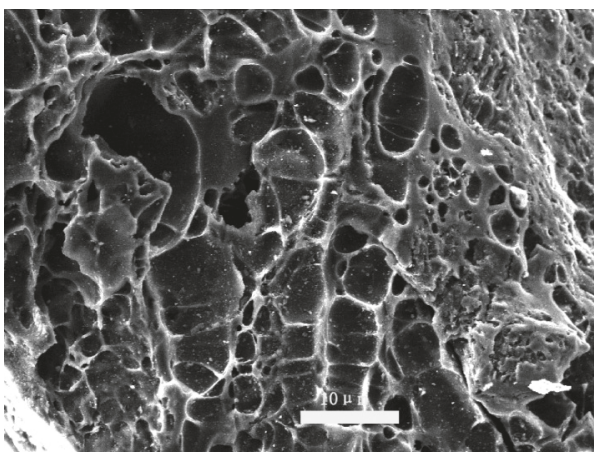

(c)

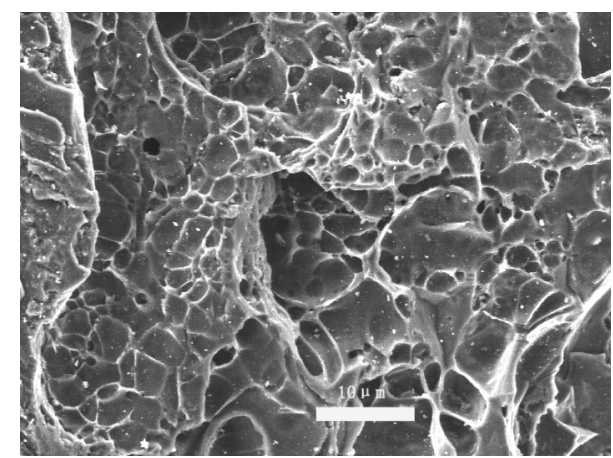

(b)

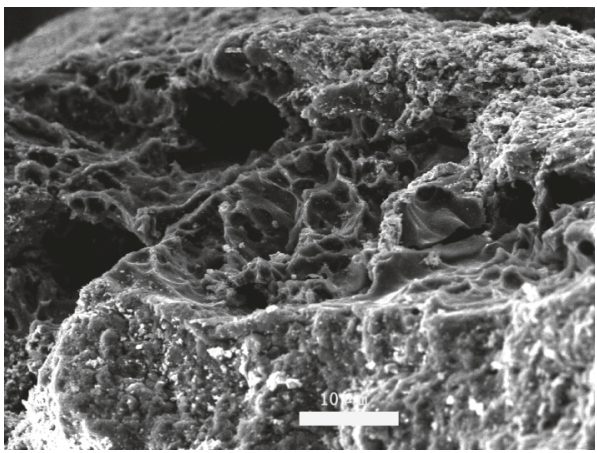

(d)

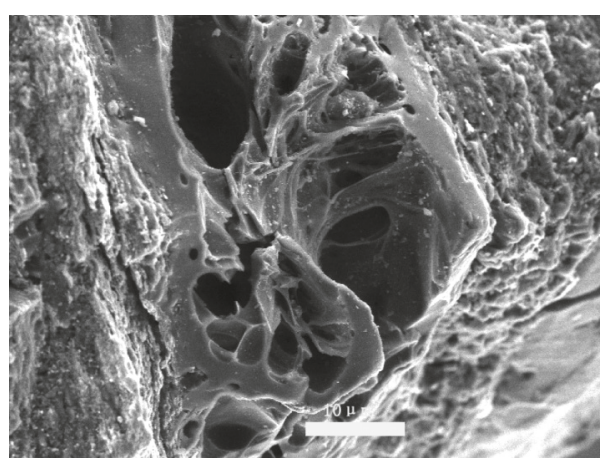

(e)

Figure 1: SEM photographs of BACs: (a) BAC-0, (b) BAC-N1, (c) BAC-N2, (d) BAC-N3, and (e) BAC-N4.

$\mathrm{C}-\mathrm{O}$ stretching vibrations, which resulted from ether linkage. However, the peak strength decreased after modification, possibly because ether linkage oxidation was continuous during nitric acid oxygenation [17]. In conclusion, the content of oxygen-containing groups evidently increased after modification.

The content of carboxyl, phenolic hydroxyl, total acid, and total basic groups on the surface of BACs can be analysed by the Boehm titration, and the results of the titration experiment are listed in Table 4. As seen from Table 4, with the increase of nitric acid concentration, the acid functional group content in the surface of BAC increased markedly, but the basicity dropped, which is consistent with the FTIR results. The carbon atom on the verge of BAC exhibited increased activity and combined with additional oxygen atoms via nitric acid oxidation, allowing additional oxygen functional group to form [18]. El-Hendawy et al. [19] found that $\mathrm{HNO}_{3}$ treatment gave rise to a greater increase in carboxylic acid, lactone, carbonyl, ethers, phenols, and hydroxyl groups in corncob-based activated carbon, which had the increase of surface acidity. The adsorption capacity of $\mathrm{Pb}^{2+}$ from aqueous solution was more than 3 times higher than unmodified.

\subsection{Effect of Modification Treatments on Adsorption}

3.2.1. Effect of Modification Conditions. The effect of modification conditions on the COD removal rate is shown in Figure 3.

Figure 3 shows that nitric acid-modified BAC exhibits better adsorption performance than unmodified. As nitric acid concentration increased, the COD removal rate initially increased and then decreased. BAC-N3 exhibited the best adsorption efficiency, and the COD removal rate was $78.70 \%$, which was higher than the unmodified BAC by 


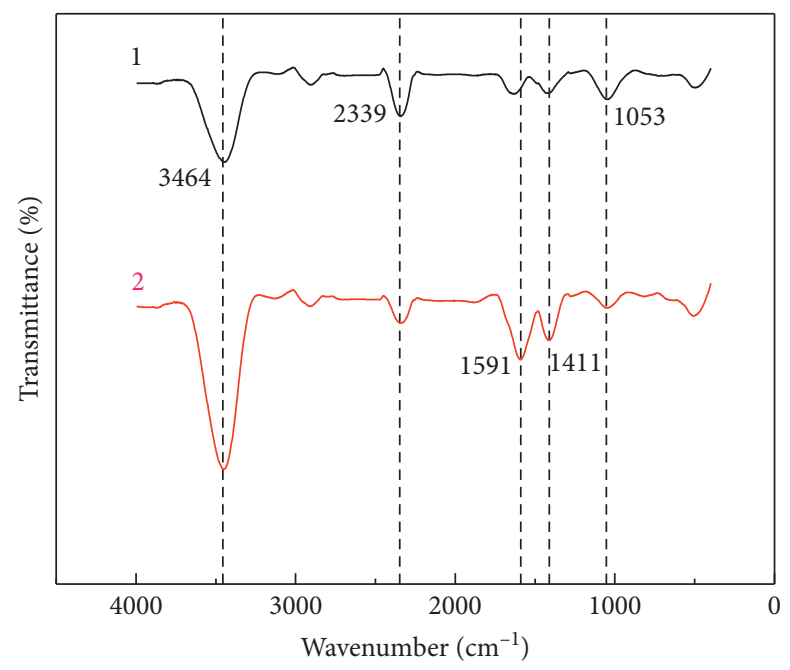

1 BAC-0

2 BAC-N3

FIgURE 2: FIIR of BAC-0 (1) and BAC-N3 (2).

TABLE 4: Content of oxygen functional groups on the surface of BACs.

\begin{tabular}{lcccc}
\hline Sample & Carboxyl $\left(\mathrm{mmol} \cdot \mathrm{g}^{-1}\right)$ & Phenolic hydroxyl $\left(\mathrm{mmol} \cdot \mathrm{g}^{-1}\right)$ & Acidity $\left(\mathrm{mmol}^{-1}\right)$ & Basicity $\left(\mathrm{mmol} \cdot \mathrm{g}^{-1}\right)$ \\
\hline BAC-0 & 0.1052 & 0.0585 & 0.1784 & 0.5875 \\
BAC-N1 & 0.6095 & 0.0676 & 0.6917 & 0.2001 \\
BAC-N2 & 0.6945 & 0.0607 & 0.7571 & 0.1792 \\
BAC-N3 & 0.7032 & 0.0540 & 0.8589 & 0.1413 \\
BAC-N4 & 0.7243 & 0.0674 & 0.8842 & 0.0986 \\
\hline
\end{tabular}

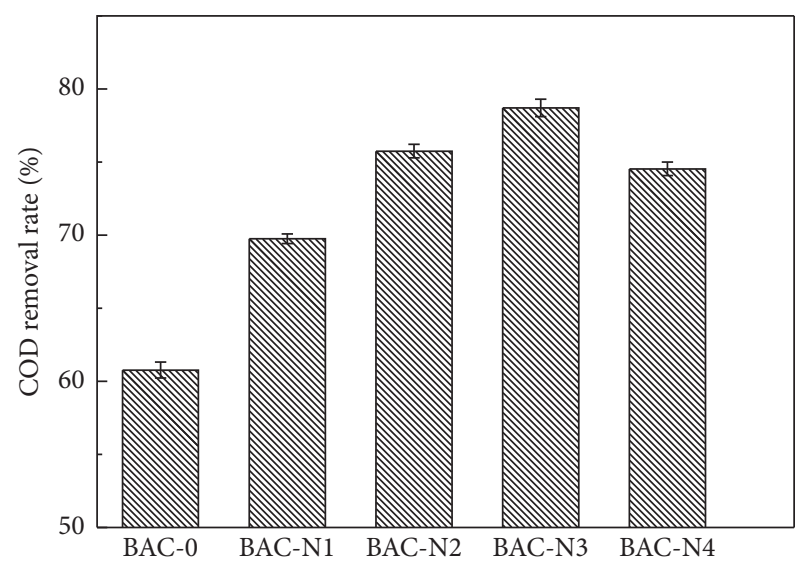

Figure 3: Effects of modification condition of BAC on the COD removal rate (the error bars indicate standard deviation of the mean of three sets of data).

22.78\%. This is because the modified BAC exhibited higher specific surface area and pore volume. The highest value of $\mathrm{COD}$ obtained in BAC-N3 indicates the best adsorption effect. Moreover, increase in the content of oxygen-containing groups enhanced the affinity on polar organic compounds, which positively affected adsorption [20]. Fan et al. [21] showed that the AC significantly affects the adsorption of organic pollutants not only because of the increased contents of carboxyl, phenol hydroxyl, and lactone groups on the AC surface but also the improvement in the surface hydrophobicity and the reduced zero point charge in the surface of AC. Tong et al. [10] suggested that oxygencontaining functional groups on the surface of AC are probably active adsorption sites. The increase in oxygencontaining functional groups may indicate the increase in active adsorption sites, which contributes to the enhancement of adsorption effect. In summary, the effect of nitric acid oxidation on the pore structure and surface chemical properties of the BAC improved the treatment efficiency of coking wastewater. Based on the experimental results, the selected nitric acid concentration was $3 \mathrm{~mol} / \mathrm{L}$.

3.2.2. Effect of Addition Amount and Adsorption Isotherm. The effect of the BAC-N3 addition amount on the COD removal rate is shown in Figure 4. As seen in Figure 4, the COD removal rate increased firstly and then became stable with the increasing amount of BAC-N3, and the process underwent the following three stages. When the addition of BAC-N3 increased from $0.5 \mathrm{~g}$ to $2 \mathrm{~g}$ per $50 \mathrm{~mL}$ of wastewater, the COD removal rate increased from $29.58 \%$ to $65.76 \%$, which is the rapid increase stage. This is because the adsorption of COD mainly depends on the number of unoccupied adsorption sites on the surface of adsorbent; the greater the amount of BAC-N3 added, the more the unoccupied adsorption sites were present. In this stage, the pollutants easily adsorbed in coking wastewater were 


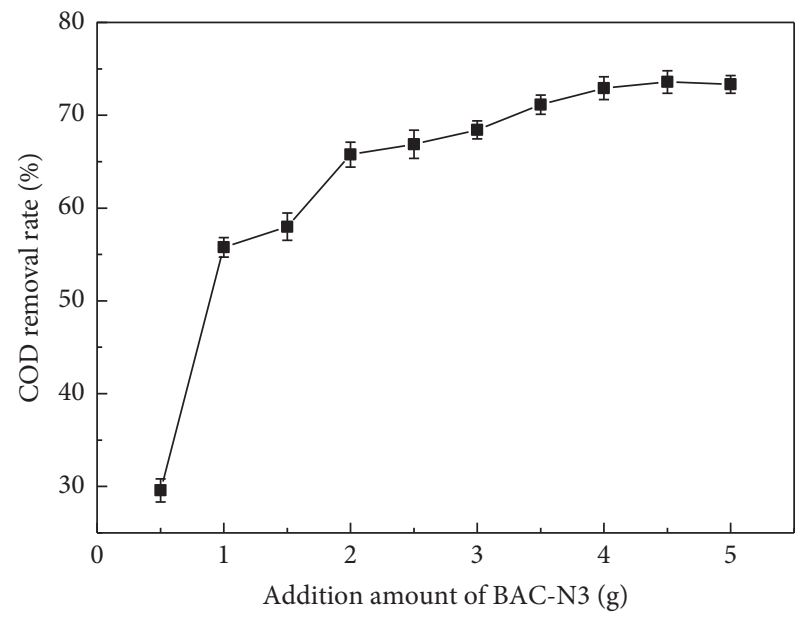

FIgURE 4: Effects of addition amount on the COD removal rate (the error bars indicate standard deviation of the mean of three sets of data).

rapidly attached to the surface of BAC-N3. When BAC-N3 has been increased to $4 \mathrm{~g}$, the increasing speed of the COD removal rate slowed down, which is the increasing slowed down stage. When adsorbent continues to rise, the COD removal rate almost does not increase, which is the adsorption stabilization stage. Although the active sites further increased with the addition of BAC-N3, the concentration of organic matter between adsorbents and adsorbate closes to accordant, which caused the decreased concentration gradient and diffuse motivation [22], and the growth in COD removal rate slowed down or remained stable. After comprehensive analysis of adsorption effect and cost factor, it can be concluded that the optimal amount of BAC-N3 is $4 \mathrm{~g}$ in $50 \mathrm{~mL}$ of coking wastewater.

Two models of Langmuir and Freundlich equations were used to fit the isothermal adsorption process of BAC-N3 on coking wastewater at $298 \mathrm{~K}$. The Langmuir equation is based on the adsorption model of a monomolecular layer. According to the mode, the surface of adsorbents is uniform, which allows no competition and indiscrimination in all of the adsorption sites and exhibits the same chemical properties [23]. Freundlich equation assumes that the structure in the surface of adsorbents is nonhomogeneous and that many interactions exist between adsorbents and adsorbate or among adsorbates. The results of the fitting are shown in Figure 5 and Table 5:

$$
\begin{gathered}
\text { Langmuir equation: } \frac{1}{q_{e}}=\frac{1}{q_{m}}+\frac{1}{q_{m} a c_{e}}, \\
\text { Freundlich equation: } \lg q_{e}=\frac{1}{n} \lg c_{e}+\lg K_{F},
\end{gathered}
$$

where $q_{m}$ is the maximum adsorption capacity $(\mathrm{mg} / \mathrm{g}), a$ is the Langmuir constant $\left(\mathrm{L} \cdot \mathrm{mg}^{-1}\right)$, and $K_{F}$ and $n$ are the adsorption constants.

The linear regression constant $\left(R^{2}\right)$ of Langmuir equations is higher than that of Freundlich equations, as illustrated in Figure 5; this shows that the adsorption equilibrium data were fitted with the Langmuir equation well, and the adsorption involved monolayer adsorption [24, 25]. The maximum adsorption capacity at $298 \mathrm{~K}$, as calculated by the Langmuir model, was $115.69 \mathrm{mg} \cdot \mathrm{g}^{-1}$, which is coincided with the experimental data $\left(106.6 \mathrm{mg} \cdot \mathrm{g}^{-1}\right)$. The constant $n^{-1}$ in the Freundlich equation is the constant which could characterize the affinity between the adsorbent and the adsorbate in the system; furthermore, this constant could also affect the extent of the difficulty in the adsorption process [26], and absorption was easily performed when $0.1<\mathrm{n}^{-1}<5$; however, adsorption forces weakened and pollutants became extremely difficult to expunge when $n^{-1}>2[24,27]$. As calculated by the Freundlich equation, $n^{-1}=0.428$, proving that the pollutants were easily anchored to the BAC-N3.

3.2.3. Effect of Shaking Speed. The effect of the shaking speed on the COD removal rate at $25^{\circ} \mathrm{C}$ is shown in Figure 6. It can be seen that the adsorption effect improves as shock speed increases from $0 \mathrm{rpm}$ to $100 \mathrm{rpm}$ or $200 \mathrm{rpm}$.

In static conditions, adsorption equilibrium at $90 \mathrm{~min}$ was reached, but the COD removal rate was only $43.07 \%$. When the shaking speed was increased to $100 \mathrm{rpm}$, the equilibrium adsorption rate was $75.62 \%$ at $120 \mathrm{~min}$, which was increased by $34.91 \%$ relative to that at $0 \mathrm{rpm}$. However, the COD removal rate decreased as the adsorption time increased. Adsorption equilibrium was reached after $150 \mathrm{~min}$ of shaking at a shaking speed of $200 \mathrm{rpm}$. During this time, the COD removal rate was $72.34 \%$, which increased by $2.4 \%$ relative to that obtained at $100 \mathrm{rpm}$. This is because the interaction between BAC-N3 and wastewater was improved via rapid shaking, allowing sufficient contact sites between the adsorption sites and the pollutant. However, when the number of adsorption sites stopped increasing, the adsorption effect became less obvious as the shaking speed continuously increased. Moreover, adsorbent collides with each other more violently with the shaking speed gone up, which was easy to break up the BAC into small particles or powder, and the adsorption effectiveness would be affected. Considering adsorption effect and energy consumption, the ideal shaking speed was $100 \mathrm{rpm}$, and the BAC-N3 adsorption to COD reached equilibrium after $120 \mathrm{~min}$.

3.2.4. Adsorption Kinetics. Kinetics studies were performed using four ordinary models such as pseudo-second-order model, Bangham model, Elovich model, and intraparticle diffusion model at different shaking speeds. The fitting results are shown in Tables 6 and 7 and Figure 7.

$$
\text { Pseudo-second-order kinetic: } \frac{t}{q_{t}}=\frac{1}{K_{2} q_{e}^{2}}+\frac{t}{q_{e}},
$$

where $K_{2}$ is the adsorption rate constant of the pseudosecond-order kinetic model $(\mathrm{g} /(\mathrm{mg} \cdot \mathrm{h}))$.

$$
\text { Elovich model: } q_{t}=A+K_{e} \ln t,
$$

where $K_{e}$ is the adsorption rate constant of the Elovich model $(\mathrm{g} /(\mathrm{mg} \cdot \mathrm{h}))$ and $A$ is a constant. 


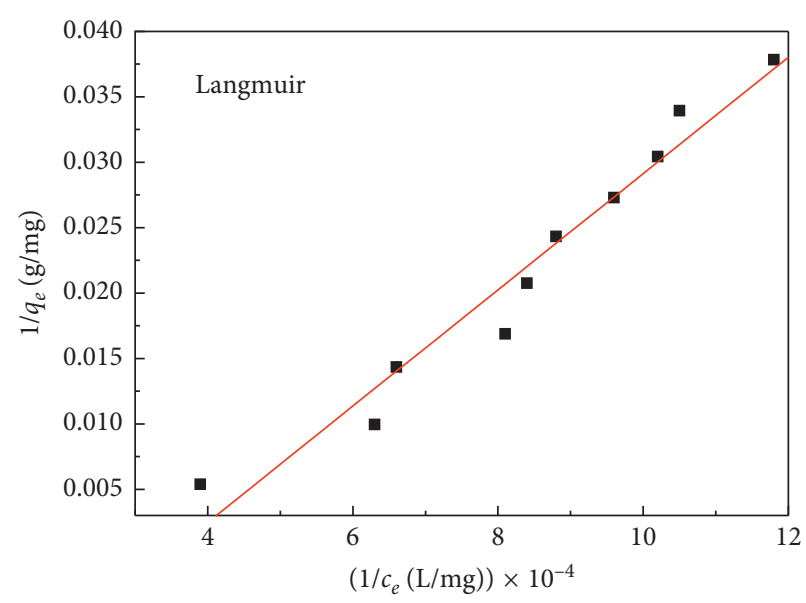

(a)

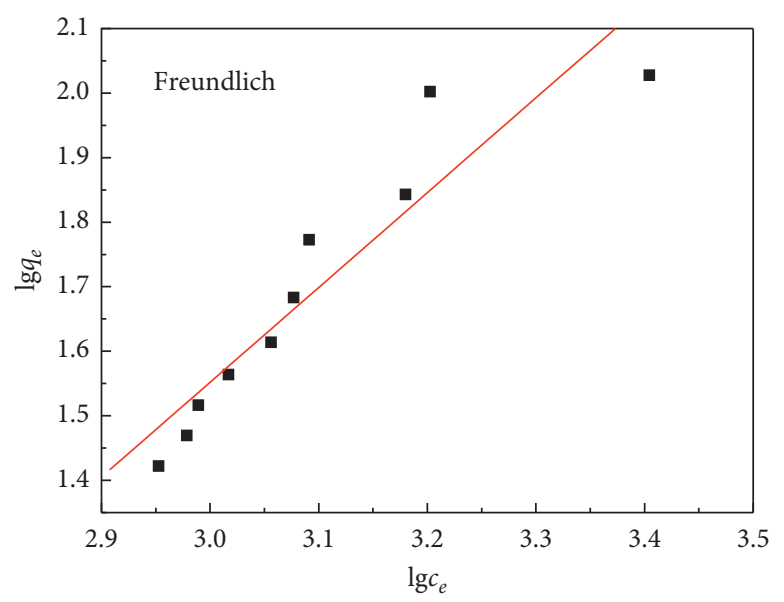

(b)

Figure 5: Adsorption isotherm: (a) Langmuir equation; (b) Freundlich equation.

TABLE 5: Adsorption isotherm parameter.

\begin{tabular}{lccccc}
\hline \multicolumn{2}{c}{ Langmuir equation } & \multicolumn{4}{c}{ Freundlich equation } \\
$q_{\mathrm{m}}\left(\mathrm{mg} \cdot \mathrm{g}^{-1}\right)$ & $a\left(\mathrm{~L} \cdot \mathrm{mg}^{-1}\right)$ & $R^{2}$ & $K_{\mathrm{F}}$ & $n^{-1}$ & $R^{2}$ \\
\hline 115.69 & $2.06 \times 10^{-3}$ & 0.9786 & 126.18 & 0.428 & 0.9337 \\
\hline
\end{tabular}

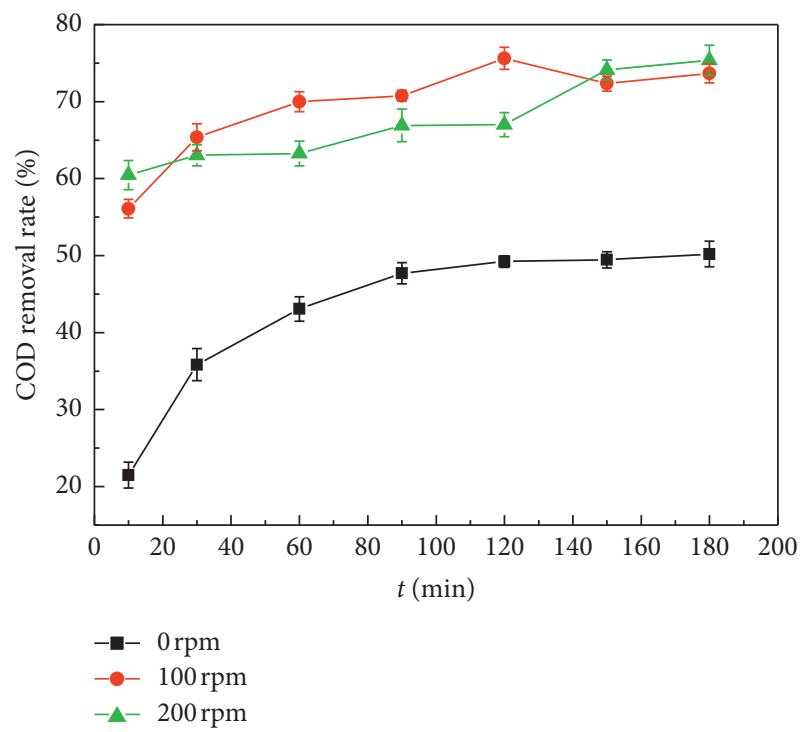

FIGURE 6: Effects of shaking speed on the COD removal rate (the error bars indicate standard deviation of the mean of three sets of data).

$$
\text { Bangham model: } \lg q_{t}=\lg k+\frac{1}{m} \lg t,
$$

where $m^{-1}$ is the adsorption rate constant of the Bangham model $(\mathrm{g} /(\mathrm{mg} \cdot \mathrm{h}))$ and $k$ is a constant.

$$
\text { Intraparticle diffusion model: } q_{t}=K_{p} t^{1 / 2}+C \text {, }
$$

where $K_{p}$ is the adsorption rate constant of the intraparticle diffusion model $\left(\mathrm{mg} /\left(\mathrm{g} \cdot \mathrm{h}^{0.5}\right)\right)$ and $C$ is a constant.

The results of the kinetic studies showed that the adsorption process of coking wastewater by BAC-N3 followed the pseudo-second-order kinetic model. Some corresponding dynamic parameters were obtained, and the linear regression constant $R^{2}$ was $>99 \%$. The equilibrium adsorption capacity fitting by using the model was consistent with the experimental values $(0 \mathrm{rpm}: 22.18 \mathrm{mg} / \mathrm{g}, 100 \mathrm{rpm}$ : $34.07 \mathrm{mg} / \mathrm{g}$, and $200 \mathrm{rpm}: 33.39 \mathrm{mg} / \mathrm{g}$ ). The pseudo-secondorder model could comprehensively affect all adsorption processes, such as liquid film diffusion, particle diffusion, and surface adsorption. Moreover, this model is applicable for the reaction of existing saturation adsorption sites, and the adsorption rate is decided by the square of adsorptive vacancy not occupied in the surface of adsorbents [28]. Tofighy et al. [29] found that the motive force of the pseudosecond-order model is the actions of ionic bonds and covalent bonds between adsorbate and adsorbent, which can conclude the main motive force of BAC adsorption for the removal of COD in coking wastewater is chemisorption processes.

The adsorption mechanism and rate-controlling step can be analysed by the intraparticle diffusion model. As shown in Table 7 and Figure 7, there is a dual linear relation in the adsorption process. The pollutants exist in coking wastewater spread to the adsorbent surface in the first stage, and the second stage indicated that the pollutants were absorbed gradually in adsorbents. Intraparticle diffusion plays a leading role in this stage. Moreover, the slope of the first stage $\left(k_{\mathrm{p} 1}\right)$ is larger than that of the second stage $\left(k_{\mathrm{p} 2}\right)$, which shows that the adsorption rate in the first stage is higher. This is possibly because of a large number of unoccupied active sites in adsorbents at the beginning of adsorption. When adsorption of the pollutant on BAC-N3 surface reached saturation, intraparticle diffusion occurred. In this time, the 
TABLE 6: Kinetic parameters of adsorption using pseudo-second-order model, Elovich kinetic model, and Bangham kinetic model.

\begin{tabular}{lccccccccc}
\hline \multirow{2}{*}{ Shaking speed $(\mathrm{rpm})$} & \multicolumn{3}{c}{ Pseudo-second-order model } & \multicolumn{3}{c}{ Elovich kinetic model } & \multicolumn{3}{c}{ Bangham kinetic model } \\
& $q_{\mathrm{e}}\left(\mathrm{mg} \cdot \mathrm{g}^{-1}\right)$ & $K_{2}(\mathrm{~g} /(\mathrm{mg} \cdot \mathrm{h}))$ & $R^{2}$ & $k_{\mathrm{e}}(\mathrm{g} /(\mathrm{mg} \cdot \mathrm{h}))$ & $A$ & $R^{2}$ & $k(\mathrm{~g} /(\mathrm{mg} \cdot \mathrm{h}))$ & $m$ & $R^{2}$ \\
\hline 0 & 24.528 & 0.0028 & 0.9994 & 4.5270 & 0.1538 & 0.9831 & 5.5101 & 3.4642 & 0.9641 \\
100 & 33.602 & 0.0089 & 0.9993 & 2.6838 & 19.909 & 0.9279 & 21.125 & 10.903 & 0.9298 \\
200 & 34.483 & 0.0034 & 0.9959 & 2.1392 & 21.308 & 0.8602 & 22.434 & 14.126 & 0.8733 \\
\hline
\end{tabular}

TABLE 7: Kinetic parameters of adsorption using the intraparticle diffusion model.

\begin{tabular}{lccccrr}
\hline \multirow{2}{*}{ Shaking speed $(\mathrm{rpm})$} & \multicolumn{4}{c}{ Intraparticle diffusion model } \\
& $k_{\mathrm{p} 1}$ & $C_{1}$ & $R^{2}$ & $k_{\mathrm{p} 2}$ & $C_{2}$ \\
\hline 0 & 1.8389 & 4.7896 & 0.9799 & 0.1074 & 20.9996 \\
100 & 1.3427 & 21.3931 & 0.9916 & 0.5324 & 26.0552 \\
200 & 1.5439 & 25.9375 & 0.9372 & 0.4070 & 13.6655 & 0.9983 \\
\hline
\end{tabular}

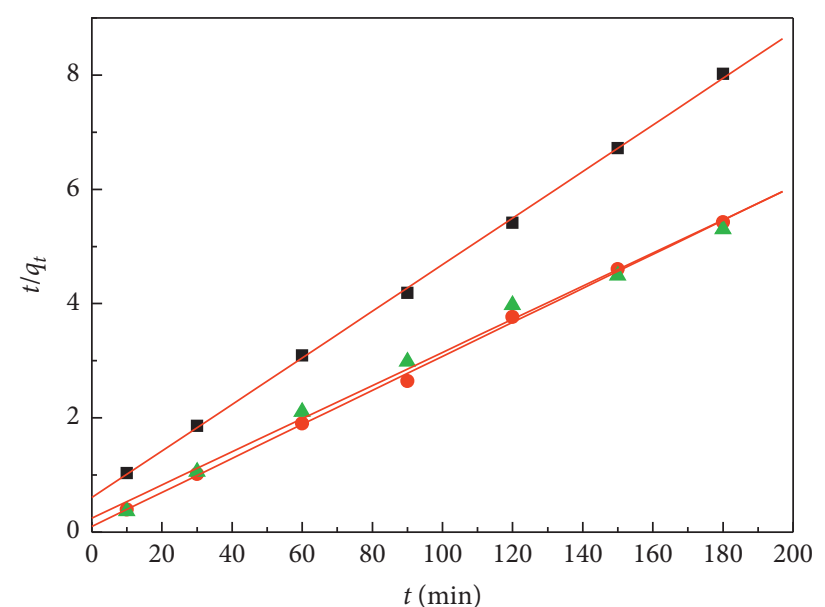

- $0 \mathrm{rpm}$

- $100 \mathrm{rpm}$

- $200 \mathrm{rpm}$

(a)

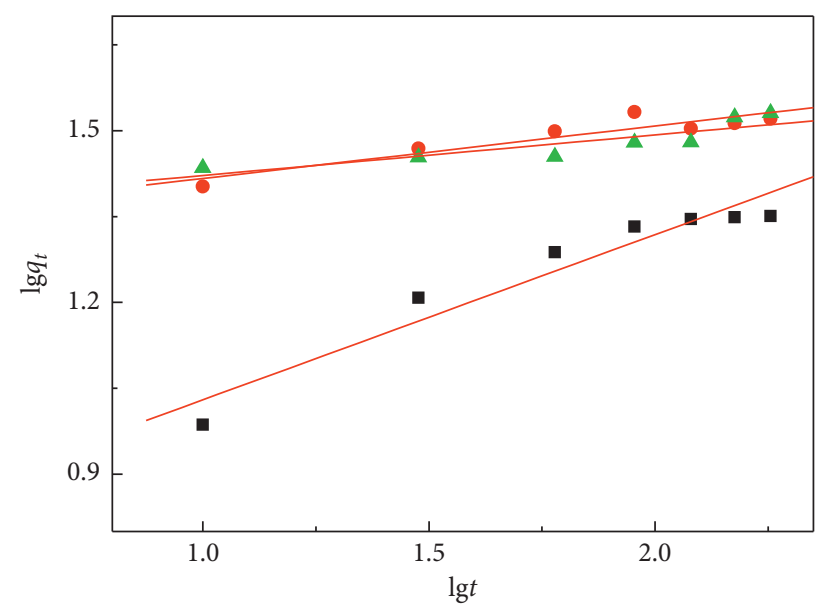

- $0 \mathrm{rpm}$

- $100 \mathrm{rpm}$

- $200 \mathrm{rpm}$

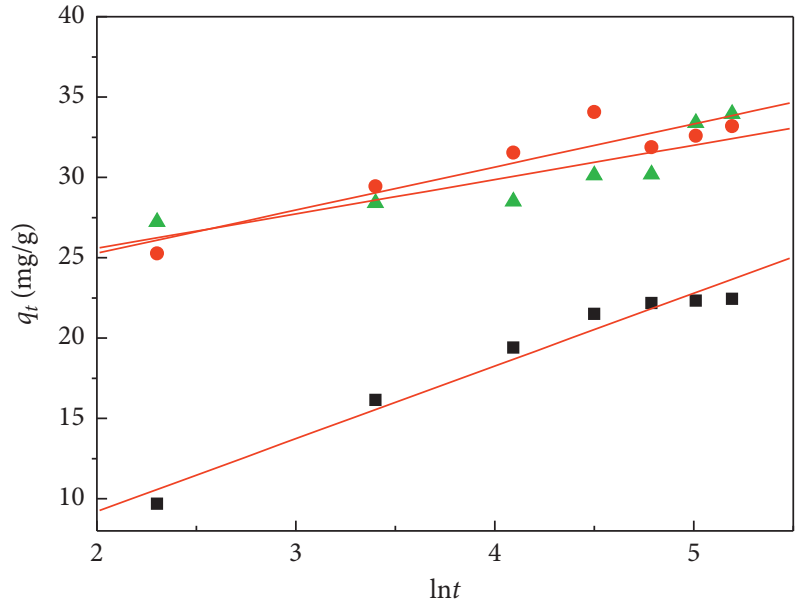

- $0 \mathrm{rpm}$

- $100 \mathrm{rpm}$

- $200 \mathrm{rpm}$

(b)

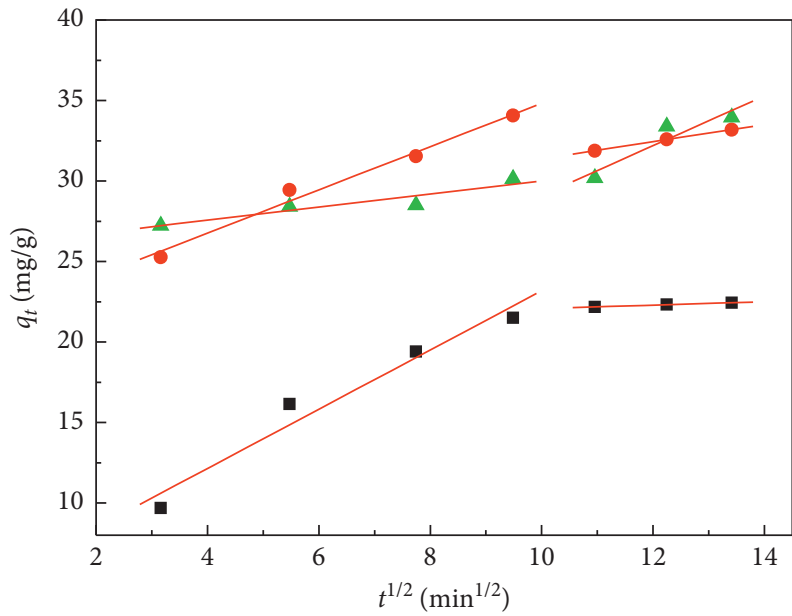

- $0 \mathrm{rpm}$

- $100 \mathrm{rpm}$

- $200 \mathrm{rpm}$

(c)

(d)

Figure 7: Fitting curves of adsorption kinetic equations: (a) pseudo-second-order kinetic model; (b) Elovich model; (c) Bangham model; (d) intraparticle diffusion model. 
adsorption resistance increased, which causes adsorption rate to decline.

\section{Conclusions}

In this work, BAC was developed by nitric acid modification at different concentrations for coking wastewater treatment. The BACs' pore structure, surface chemical properties, and their ability to remove COD from coking wastewater were investigated. The effects of nitric acid concentration, addition amount, shaking speed, and adsorption time were studied. And the adsorption isotherm and thermodynamics of the adsorption process were studied. The conclusions are as follows:

(1) After modification by nitric acid, the BET specific surface area, iodine adsorption value, and the oxygen-containing functional groups of BAC increase, and the adsorption effect of COD from coking wastewater was also better. The best modification effect was obtained under the $3 \mathrm{~mol} / \mathrm{L}$. At this time, the COD removal rate was improved by $22.78 \%$ relative to that of unmodified BAC.

(2) The optimized conditions for the adsorption of coking wastewater were as follows: $4 \mathrm{~g}$ of additional BAC-N3 per $50 \mathrm{~mL}$ of coking wastewater, $100 \mathrm{rpm}$ shaking speed, and $120 \mathrm{~min}$ adsorption time; the COD removal rate is $77.05 \%$, and the adsorption effect was better than that of chitosan flocculent [30], coke powder [31], and some coal-based adsorbent [32].

(3) The adsorption process was fitted by the pseudosecond-order kinetic model, and the Langmuir equation could better describe equilibrium adsorption data compared with the Freundlich equation.

\section{Data Availability}

The data used to support the findings of this study are available from the corresponding author upon request.

\section{Conflicts of Interest}

The authors declare that they have no conflicts of interest regarding the publication of this article.

\section{Acknowledgments}

The authors wish to thank the Science and Technology Projects of Xianyang (2018k02-19) for their financial support of this work.

\section{References}

[1] X. Jiang, X. Z. Lan, X. P. Jing, Y. H. Song, and X. D. Xing, "Research on experiment of blue coke-based activated carbon by physical activation in different medium," Coal Conversion, vol. 42, no. 2, pp. 65-71, 2019.

[2] Y. H. Song, Q. N. Ma, X. Li, J. Zhou, and Y. H. Tian, "The Influence of activation temperature on structure and properties of semi-coke-based activated carbon," Materials Review, vol. 30, no. 1, pp. 34-37, 2016.

[3] S. R. Sivakkumar and A. G. Pandolfo, "Evaluation of lithiumion capacitors assembled with pre-lithiated graphite anode and activated carbon cathode," Electrochimica Acta, vol. 65, no. 30, pp. 280-287, 2012.

[4] Y. N. Ye, L. J. Chen, L. Q. Liu et al., "Effect of preparation procedure of coal-based activated carbons on iodine adsorption," Materials Review, vol. 29, no. s1, p. 327, 2015.

[5] M.-X. Wang, C.-Y. Wang, M.-M. Chen et al., "Preparation of high-performance activated carbons for electric double layer capacitors by $\mathrm{KOH}$ activation of mesophase pitches," New Carbon Materials, vol. 25, no. 4, pp. 285-290, 2010.

[6] Y. H. Song, L. Zhang, X. Jiang, and Y. H. Tian, "Effect of reaction temperature on activated carbon by steam activation from blue-coke powder," Coal Conversion, vol. 40, no. 5, pp. 56-62, 2017.

[7] Y. H. Tian, X. Z. Lan, J. Zhou, X. Y. Chen, and J. Zhou, "Reparation of activated carbon from blue coke powder by microwave radiation and $\mathrm{KOH}$ activation," Chemical Engineering, vol. 38, no. 10, pp. 225-228, 2010.

[8] N. Wibowo, L. Setyadhi, D. Wibowo, J. Setiawan, S. Ismadji et al., "Adsorption of benzene and toluene from aqueous solutions onto activated carbon and its acid and heat treated formls: influence of surface chemistry on adsorption," Journal of Hazardous Materials, vol. 146, no. 1-2, pp. 237-242, 2007.

[9] S. M. Soltani, S. K. Yazdi, S. Hosseini, and M. K. Gargari, "Effect of nitric acid modification on porous characteristics of mesoporous char synthesized from the pyrolysis of used cigarette filters," Journal of Environmental Chemical Engineering, vol. 2, no. 3, pp. 1301-1308, 2014.

[10] L. Tong, W. Q. Xu, H. Qi et al., "Enhanced effect of O/N groups on the $\mathrm{Hg}$ removal efficiency over the $\mathrm{HNO}_{3}$-modified activated carbon," Acta Physico-Chimica Sinica, vol. 31, no. 3, pp. 512-518, 2015.

[11] Z. G. Zhang, Y. Y. Ma, J. G. Fan, X. L. Sun, and W. X. Li, "Adsorption of benzothiophene in simulated gasoline on nitric acid modified activated carbon," Acta Petrolei Sinica (Petroleum Processing Section), vol. 30, no. 1, pp. 47-52, 2014.

[12] S. Babel and T. A. Kurniawan, "Cr(VI) removal from synthetic wastewater using coconut shell charcoal and commercial activated carbon modified with oxidizing agents and/or chitosan," Chemosphere, vol. 54, no. 7, pp. 951-967, 2004.

[13] C. H. Wei, M. H. He, Y. Ren, B. G. Li, and J. G. Chen, "Pollution characteristics of coking wastewater and control strategies: biological treatment process and technology," Acta Scientiae Circumstantiae, vol. 27, no. 7, pp. 1083-1093, 2007.

[14] M. Seredych and T. J. Bandosz, "Adsorption of dibenzothiophenes on nanoporous carbons: identification of specific adsorption sites governing capacity and selectivity," Energy \& Fuels, vol. 24, no. 6, pp. 3352-3360, 2010.

[15] A. Gil, G. De La Puenti, and P. Grange, "Evidence of textural modifications of an activated carbon on liquid phase oxidation treatments," Micorporus Materials, vol. 12, no. 1-3, pp. 51-61, 1997.

[16] X. Lan, X. Jiang, Y. Song, X. Jing, and X. Xing, “The effect of activation temperature on structure and properties of blue coke-based activated carbon by $\mathrm{CO}_{2}$ activation," Green Processing and Synthesis, vol. 8, no. 1, pp. 837-845, 2019.

[17] L. A. Laura and D. H. Fairbrother, "Effect of wet chemical treatments on the distribution of surface oxides on carbonaceous materials," Carbon, vol. 45, no. 1, pp. 47-54, 2007.

[18] V. L. Snoeyink and W. J. Weber, "The surface chemistry of active carbon; a discussion of structure and surface functional 
groups," Environmental Science \& Technology, vol. 1, no. 3, pp. 228-234, 1967.

[19] A.-N. A. EL-Hendawy, "Influence of $\mathrm{HNO} 3$ oxidation on the structure and adsorptive properties of corncob-based activated carbon," Carbon, vol. 41, no. 4, pp. 713-722, 2003.

[20] M. Seredych, J. Lison, U. Jans, and T. J. Bandosz, "Textural and chemical factors affecting adsorption capacity of activated carbon in highly efficient desulfurization of diesel fuel," Carbon, vol. 47, no. 10, pp. 2491-2500, 2009.

[21] Y. Z. Fan, B. Z. Wang, L. Wang, and M. Yu, "Adsorption of organic micropollutants on modified activated carbons," Environmental Chemistry, vol. 20, no. 5, pp. 444-448, 2001.

[22] W. W. Gao, Y. Gong, Y. N. Gao, B. Chen, and X. Jiang, "I Adsorption of semi-coking wastewater on activated carbon loaded cerium and manganese," Bulletin of the Chinese Ceramic Society, vol. 36, no. 1, pp. 197-204, 2017.

[23] J. Liu, Y. Feng, X. W. Tan, Y. Yan, and H. P. Zhang, “Adsorption of EDTA wastewater by acid modified activated carbon," Materials Review, vol. 29, no. 10, pp. 81-86, 2015.

[24] X. Liang, L. Q. Li, Z. Liu et al., "Effect of microwave and alkaline solution modification activated carbons on adsorption properties of actone acetone," Journal of Central South University (Science and Technology), vol. 46, no. 2, pp. 743750, 2015.

[25] V. Vimonses, S. Lei, B. Jin, C. W. K. Chow, and C. Saint, "Kinetic study and equilibrium isotherm analysis of Congo Red adsorption by clay materials," Chemical Engineering Journal, vol. 148, no. 2-3, pp. 354-364, 2009.

[26] J. Liu, Q. X. Zhu, X. W. Tan, Y. Yan, and H. P. Zhang, "Adsorption of methyl orange on modified activated carbon," The Chinese Journal of Process Engineering, vol. 16, no. 2, pp. 222-227, 2016.

[27] M. Sarkar and P. Majumdar, "Application of response surface methodology for optimization of heavy metal biosorption using surfactant modified chitosan bead," Chemical Engineering Journal, vol. 175, no. 15, pp. 376-387, 2011.

[28] W. W. Gao, T. Su, Y. Gong et al., "Study of adsorption property of coking wastewater on activated carbon loaded copper," Non-Metallic Mines, vol. 39, no. 1, pp. 40-43, 2016.

[29] M. A. Tofighy and T. Mohammadi, "Adsorption of divalent heavy metal ions from water using carbon nanotube sheets," Journal of Hazardous Materials, vol. 185, no. 1, pp. 140-147, 2011.

[30] W. B. Ou, F. Zhu, P. Wang, and C. M. Shi, "Study of chitosan flocculant to the COD removal of coking wastewater effluent," Science Technology and Engineering, vol. 14, no. 21, pp. 167172, 2014.

[31] B. H. Yan, X. L. Li, Q. Jiang, L. Xu, and X. X. Ma, "Study on advanced treatment of coking wastewater by coke powder adsorption," Clean Coal Technology, vol. 25, no. 1, pp. 160$167,2019$.

[32] Z. P. Li, Q. Y. Gao, D. Chen et al., "Experimental study on treatment of coking wastewater by coal-based adsorbent," Applied Chemical Industry, vol. 48, no. 10, pp. 2403-2406, 2019. 

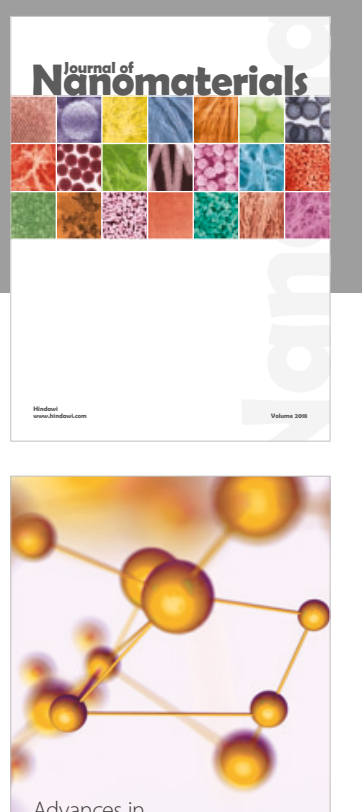

Physical Chemistry
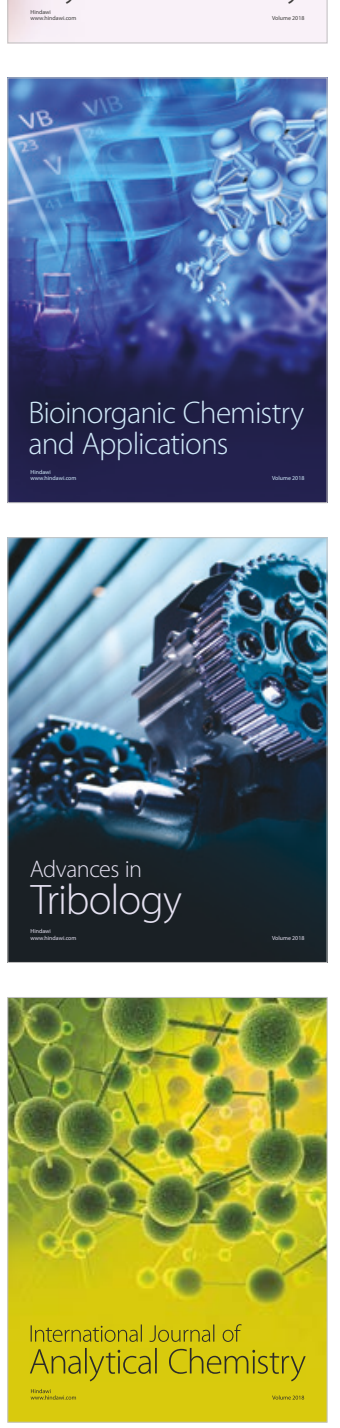

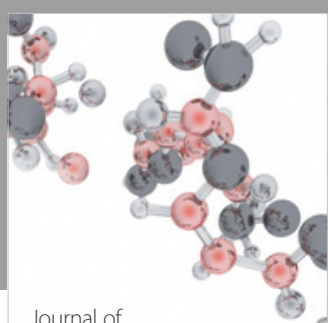

Analytical Methods

in Chemistry

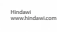

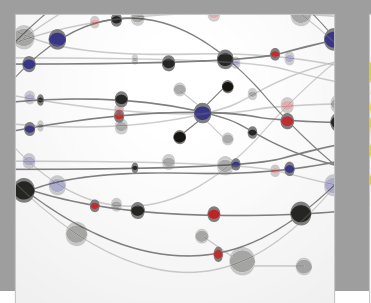

The Scientific World Journal

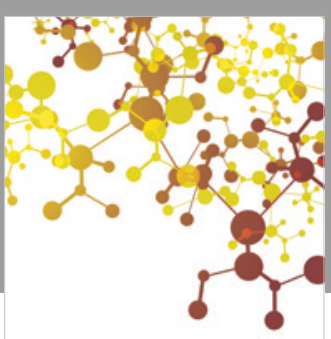

Journal of

Applied Chemistry
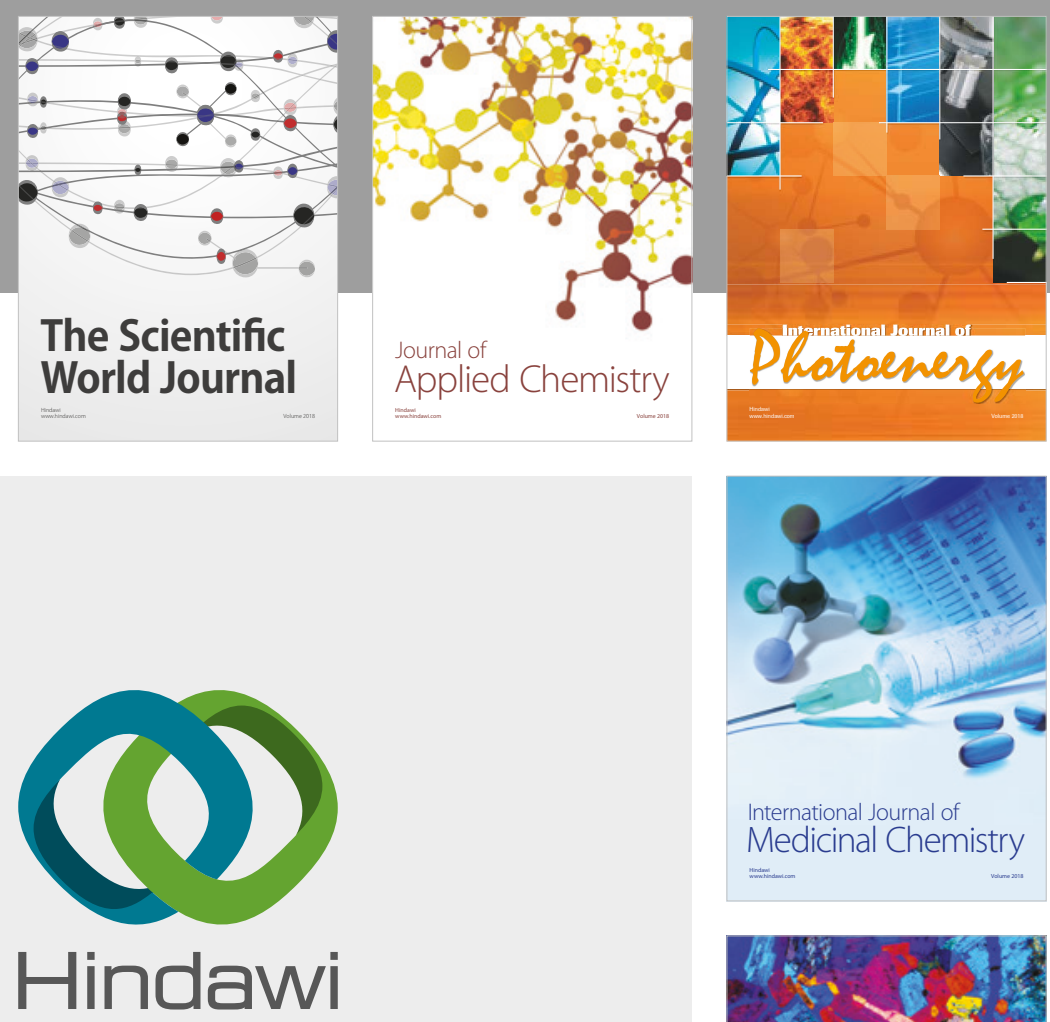

Submit your manuscripts at

www.hindawi.com
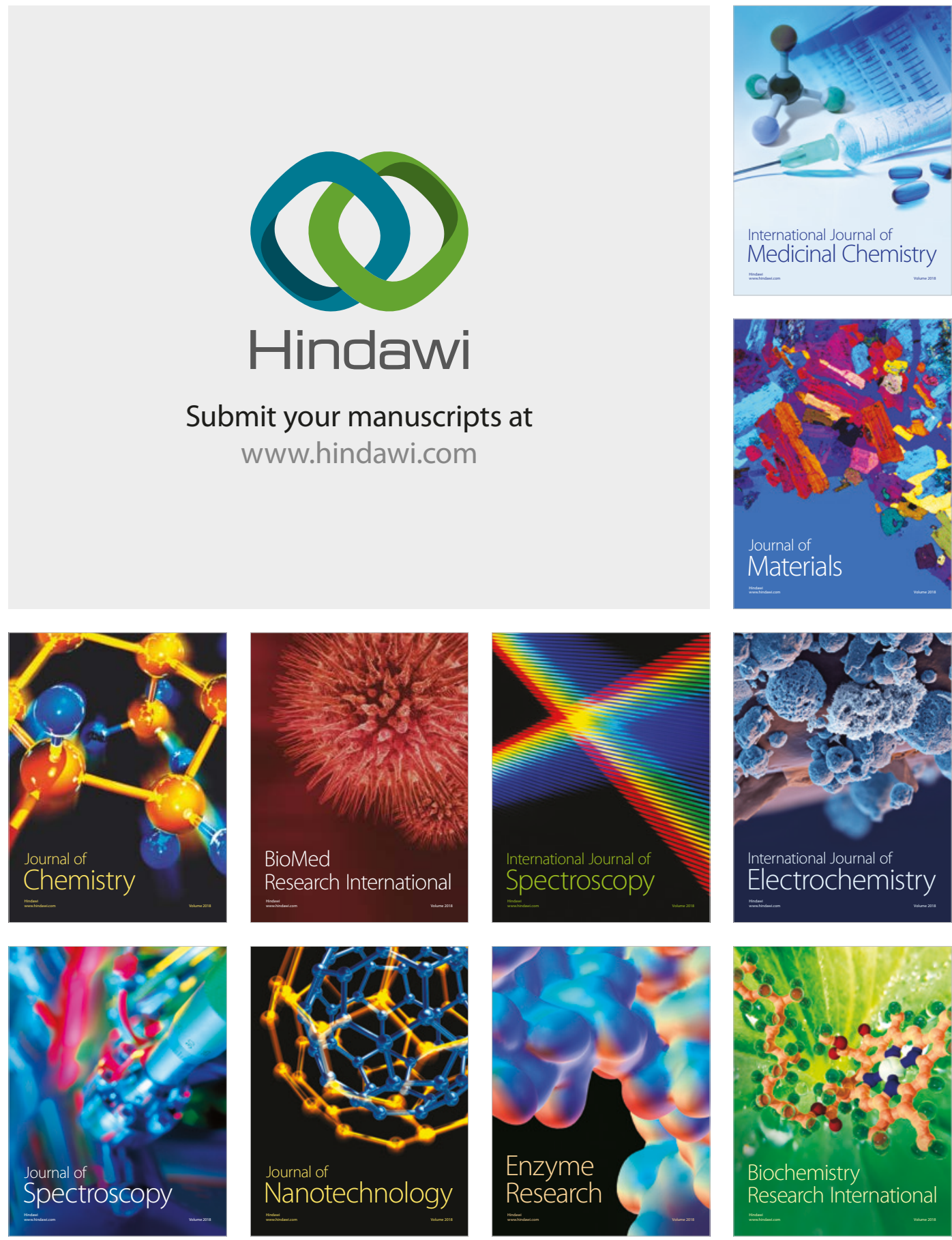
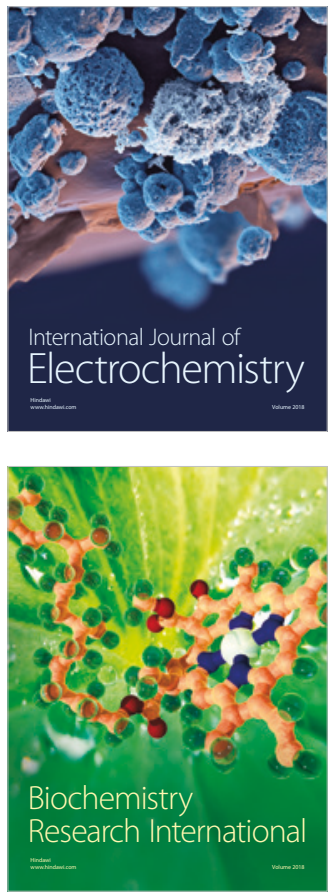